\title{
ORIGINAL ARTICLE www.elearnSCI.org: a global educational initiative of ISCoS
}

\author{
HS Chhabra ${ }^{1}$, LA Harvey ${ }^{2}$, S Muldoon ${ }^{3}$, S Chaudhary ${ }^{4}$, M Arora ${ }^{5}$, DJ Brown ${ }^{6}$, F Biering-Sorensen ${ }^{7}$, \\ JJ Wyndaele $^{8}$, S Charlifue ${ }^{9}$, J Horsewell ${ }^{10}$, S Ducharme ${ }^{11}$, D Green ${ }^{12}$, D Simpson ${ }^{13}$, J Glinsky ${ }^{14}$, E Weerts ${ }^{15}$, \\ N Upadhyay ${ }^{16}$, S Aito ${ }^{17}$, P Wing ${ }^{18}$, S Katoh ${ }^{19}$, A Kovindha ${ }^{20}$, A Krassioukov ${ }^{21}$, C Weeks ${ }^{22}$, V Srikumar ${ }^{23}$, \\ R Reeves ${ }^{24}$, C Siriwardane ${ }^{25}$, N Hasnan ${ }^{26}$, YB Kalke ${ }^{27}$ and I Lanig ${ }^{28}$
}

Objective: To develop a web-based educational resource for health professionals responsible for the management of spinal cord injury (SCl).

The resource: www.elearnSCl.org is comprised of seven learning modules, each subdivided into various submodules. Six of the seven modules address the educational needs of all disciplines involved in comprehensive SCI management. The seventh module addresses prevention of $\mathrm{SCl}$. Each submodule includes an overview, activities, self-assessment questions and references.

Development of the resource: Three hundred and thirty-two experts from The International Spinal Cord Society (ISCoS) and various affiliated societies from 36 countries were involved in developing the resource through 28 subcommittees. The content of each submodule was reviewed and approved by the Education and Scientific Committees of ISCoS and finally by an Editorial Committee of 23 experts.

Key features: The content of the learning modules is relevant to students and to new as well as experienced SCl healthcare professionals. The content is applicable globally, has received consumer input and is available at no cost. The material is presented on a website underpinned by a sophisticated content-management system, which allows easy maintenance and ready update of all the content. The resource conforms to key principles of e-learning, including appropriateness of curriculum, engagement of learners, innovative approaches, effective learning, ease of use, inclusion, assessment, coherence, consistency, transparency, cost effectiveness and feedback.

Conclusion: www.elearnSCl.org provides a cost effective way of training healthcare professionals that goes beyond the textbook and traditional face-to-face teaching.

Spinal Cord (2013) 51, 176-182; doi:10.1038/sc.2012.177

Keywords: educational resource; elearnSCl.org; comprehensive SCl management; e-learning principles; spinal cord injury

\section{INTRODUCTION}

Spinal cord injury (SCI) management remains one of the most complex challenges for healthcare professionals. It requires skilful and coordinated input from a multi-disciplinary team of health professionals ${ }^{1}$ and lifelong follow-up. ${ }^{2}$ The goal of SCI management is to increase independence, restore dignity and hope, and maximise quality of life for those living with SCI. Until now, however, there has been a lack of professional development opportunities for healthcare professionals involved in the management of SCI and limited access to up-to-date
SCI training and learning resources. This is particularly a challenge for low-resource countries and those in rural and remote areas.

Recognising the need to disseminate information about comprehensive management of SCI, the Education Committee of The International Spinal Cord Society (ISCoS) initiated and developed www.elearnSCI.org; a web-based educational resource. The aim of this resource is to increase understanding, skills and knowledge about the comprehensive management of SCI. The resource is appropriate for students and clinicians of all disciplines.

${ }^{1}$ Spine Service, Indian Spinal Injury Centre, Delhi, India; ${ }^{2}$ Rehabilitation Studies Unit, Sydney Medical School, University of Sydney, Sydney, New South Wales, Australia; ${ }^{3}$ Head of Overseas Development, Livability, Ireland; ${ }^{4}$ Project Coordinator, elearning, Indian Spinal Injury Centre, Delhi, India; ${ }^{5}$ Research Department, Indian Spinal Injury Centre, Delhi, India; ${ }^{6}$ Victorian Spinal Cord Service and Spinal Research Institute, Austin Health and University of Melbourne, Melbourne, Victoria, Australia; ${ }^{7}$ Clinic for Spinal Cord Injuries, Glostrup University Hospital and Faculty of Health Sciences, University of Copenhagen, Copenhagen, Denmark; ${ }^{8}$ Antwerp University Hospital, Edegem, Belgium; ${ }^{9}$ Craig Hospital, Englewood, CO, USA; ${ }^{10}$ European Spinal Cord Injury Federation, Notwil, Switzerland; ${ }^{11}$ Rehabilitation Medicine, Boston University School of Medicine, Boston, MA, USA; ${ }^{12}$ Spinal Outpatient Services, Outreach, Practice Development and Telemedicine, National Spinal Injuries Centre, Stoke Mandeville Hospital, London, UK; ${ }^{13}$ Royal North Shore Hospital, Sydney, New South Wales, Australia; ${ }^{14}$ Rehabilitation Studies Unit, Sydney Medical School, University of Sydney, Sydney, New South Wales, Australia; ${ }^{15}$ SCl UnitHandicap International Vietnam, Ha Noi, Vietnam; ${ }^{16}$ Department of Assistive Technology, Indian Spinal Injury Centre, Delhi, India; ${ }^{17}$ University of Florence School of Medicine, Florence, Italy; ${ }^{18}$ Division of Spine, University of British Columbia, Vancouver, British Columbia, Canada; ${ }^{19}$ Department of Rehabilitation Medicine, Tokushima University Hospital, Tokushima, Japan; ${ }^{20}$ Department of Rehabilitation Medicine, Faculty of Medicine, Chiang Mai University, Chiang Mai, Thailand; ${ }^{21}$ Department of Medicine, Division of PM\&R, University of British Columbia, Vancouver, British Columbia, Canada; ${ }^{22}$ Division of PMR, University of British Columbia, Vancouver, British Columbia, Canada, ${ }^{23}$ Department of PM\&R, VMMC \& Safdarjang Hospital, Delhi, India; ${ }^{24}$ Mayo Clinic College of Medicine, Department of Physical Medicine and Rehabilitation, Rochester, MN, USA; ${ }^{25}$ Sri Lanka Foundation for the Rehabilitation of the Disabled, Colombo, Sri Lanka; ${ }^{26}$ Department of Rehabilitation Medicine, Faculty of Medicine, University of Malaya, Kuala Lumpur, Malaysia; ${ }^{27}$ Spinal Cord Injury Centre, Orthopaedic Department, University of Ulm, Ulm, Germany and ${ }^{28}$ Northern Colorado Rehabilitation Hospital, Johnstown, CO, USA

Correspondence: Dr HS Chhabra, Spine Service, Indian Spinal Injuries Centre, Sector C, Vasant Kunj, New Delhi, Delhi 110070 , India.

E-mail: drhschhabra@isiconline.org

Received 12 November 2012; revised 30 November 2012; accepted 4 December 2012 


\section{THE CONTENT AND FORMAT OF THE RESOURCE}

www.elearnSCI.org comprises seven learning modules, each consisting of a number of submodules. The first module is titled 'Overview for the whole team' and provides basic information about the management of SCI for all disciplines. Five other modules cater to the specific educational needs of doctors, nurses, physiotherapists, occupational therapists/assistive technologists and psychologists/social workers/peer counsellors. It is recommended that users go through the first module, 'Overview for the whole team', before accessing their discipline-specific modules. The seventh module mainly focuses on information about the prevention of SCI.

The modules are comprised of various submodules (Table 1) each of which covers a specific topic and includes (Figure 1):

- an overview: this is a didactic presentation outlining the key concepts of SCI management.

- activities: these come in various forms. In some modules the activities are primarily multiple-choice questions where users receive feedback about their responses. In other modules the activities are more complex with up to 50 screens containing case studies, more in-depth information, links to other resources, videos, interviews with experts and consumers, and many different types of interactive screens.

- self-assessment questions: these are multiple choice questions. Users receive a score which is logged in their profile page. The users can elect to have their results e-mailed to anyone, for example, their supervisors, lecturers or mentors.

- references: these are the key references for the submodule.

The learning modules are accompanied by a comprehensive definition of terms, including a glossary and abbreviations.

\section{DEVELOPMENT OF THE RESOURCE}

The project was first proposed at the Education Committee meeting during the 2009 Annual Scientific Meeting of ISCoS. It was approved a year later at the ISCoS Annual Scientific Meeting in New Delhi, and work began immediately thereafter. The Asian Spinal Cord Network, Indian Spinal Injuries Centre, Livability Ireland and the New South Wales Lifetime Care and Support Scheme partnered with ISCoS to develop the content and accompanying website, with substantial financial support from Access to Health Care.

Three hundred and thirty-two experts from ISCoS and various affiliated societies in 36 countries were involved in developing the content through 28 subcommittees, each working on a particular submodule. The basic content of each submodule was developed from a 3-day workshop conducted after the 2010 ISCoS Annual Scientific Meeting titled 'Comprehensive management of SCI'. The presentations in this workshop were used as a draft by the subcommittees. The content of each submodule developed by the subcommittees was ultimately reviewed and approved by the Education and Scientific Committees of ISCoS. The modules were then trialed at a workshop in New Delhi in April 2012 and feedback was taken from over 200 delegates. An Editorial Committee of 23 experts met simultaneously during the workshop to review and edit the submodules. Editorial work continued online thereafter.

The web platform for hosting the educational resource was developed by a company in New Delhi. The content sits on a website underpinned by a sophisticated content-management system, which allows the administrators to upload, move, copy and change the content of any screen, including the interactive screens. This feature was considered important for the long-term viability of the project: it will enable ISCoS administrators to be largely independent of ongoing IT support on completion of the project.

The content was written in javascript and HTML with a SQL database. Some of the interactive screens have been written in HTML 5 code. Even though Flash can provide a good visual and interactive experience Flash was not used because it is not compatible with apple mobile devices, is not easy to maintain and cannot be used in places with slow internet connections.

www.elearnSCI.org was launched during the International Spinal Cord Society's 51st Annual Scientific Meeting in London on 4th September 2012. It will continue to evolve in the coming years. The development and widespread dissemination of the e-learning resource is an expression of the aims of ISCoS.

\section{VISION}

As the authority on the management of SCI, ISCoS will aspire to promote free and easy access to relevant educational resources on comprehensive management of SCI amongst health professionals involved in SCI management and also amongst people living with SCI, their families, health care providers, policy makers and the community in general.

\section{MISSION}

The mission of www.elearnSCI.org is to improve the quality of life of people living with SCI by disseminating awareness about SCI prevention and comprehensive management globally.

\section{KEY FEATURES OF THE RESOURCE}

www.elearnSCI.org:

- is based on evidence and the latest research thus providing the most up-to-date knowledge.

- is relevant to students as well as junior and experienced healthcare professionals.

- is free for all to access.

- is appropriate for those from high and low resource countries and for people from varying social, cultural and economic backgrounds, with content that reflects the realities of providing healthcare in both high and low resource settings (Figure 2).

- has been written in simple English with heavy reliance on illustrations and videos for those users for whom English is not their first language.

- has had consumer input. SCI consumers were involved in the compilation of the Psychologists, Social Workers and Peer Counselors module and other relevant submodules such as vocational rehabilitation and community inclusion. In addition, consumers were represented on the editorial committee ensuring their perspectives were appropriately reflected in all content.

- is underpinned by a sophisticated content management system, which enables ISCoS administrators to change and update content without IT support, thus saving costs.

- complies with the principles of effective e-learning (Figure 3).

\section{COMPLIANCE WITH PRINCIPLES OF E-LEARNING}

The resource conforms with the widely acknowledged principles of effective e-learning ${ }^{3-11}$ that includes the following.

\section{Appropriateness of curriculum}

The content. The content was developed to provide comprehensive information on the management of SCI appropriate for all members of the team. ${ }^{3}$ The content of each submodule has been compiled by 
Table 1 Depicts the sub-modules of each of the seven modules

Introduction to $\mathrm{SCl}$

Team-based care - roles and responsibilities

Prehospital care

Emergency and acute care management of $\mathrm{SCl}$

Clinical assessment of patients with $\mathrm{SCl}$

Management of vertebral lesion

Respiratory management

Nutritional management

Bladder management

Bowel care and management

Sexuality, fertility and $\mathrm{SCl}$

Early and late complications in $\mathrm{SCl}$

Autonomic dysreflexia

\section{Overview for the whole team module}

Nursing management

Physiotherapy management

Occupational therapy management

Assistive technology perspective and mobility and seating

Psychosocial rehabilitation and team

Communication skills for healthcare professionals

Community inclusion

Outcomes in $\mathrm{SCl}$

Vocational rehabilitation

Issues specific to women with $\mathrm{SCl}$

Prevention of $\mathrm{SCl}$

Cell transplant therapy

Management of $\mathrm{SCl}$ after disasters and emergencies

\section{Doctors' module}

Prehospital care

Clinical assessment of patients with $\mathrm{SCl}$

Emergency and acute care management of $\mathrm{SCl}$

Management of vertebral lesion

Respiratory management

Nutritional management

Bladder management

Bowel care and management

Sexuality, fertility and $\mathrm{SCl}$

Early and late complications in $\mathrm{SCl}$ : musculoskeleta
Early and late complications in SCl: pain

Early and late complications in $\mathrm{SCl}$ : respiratory

Early and late complications in $\mathrm{SCl}$ : cardiovascular

Early and late complications in $\mathrm{SCl}$ : genitourinary tract and neurogenic bladder

Early and late complications in $\mathrm{SCl}$ : spasticity

Early and late complications in $\mathrm{SCl}$ : pressure ulcer infection and sepsis

Psychiatric management of depression

Management of pediatric SCl

Aging with $\mathrm{SCl}$

Cell transplant therapy

\section{Physiotherapists' module}

The health essentials

Principles of management

Assessment

Setting goals

Bed mobility and transfers: understanding movement Wheelchair mobility: understanding movement

Gait: understanding movement

\section{Nurses' module}

Introduction to the concept and role of the nurse Spinal precautions

Maintaining skin integrity following $\mathrm{SCl}$

Respiratory function

Haemodynamic and cardiovascular issues following $\mathrm{SCl}$

Genitourinary system and bladder management

Managing neurogenic bowel dysfunction in people with $\mathrm{SCl}$

The role of nurses in facilitating healthy sexuality in people with $\mathrm{SCl}$

\section{Psychologists', social workers' and peer counselors' module}

Psychosocial adjustment to $\mathrm{SCl}$

Psychosocial issues regarding family members

Psychosocial response to an activity of rehabilitation

Family care giving and $\mathrm{SCl}$

Psychosocial response to medical complications of $\mathrm{SCl}$

Core element of counselling

Peer counseling: a holistic psycho-social rehabilitation approach
Upper limb function: understanding movement

Strength: assessing and treating

Contractures: assessing and treating

Motor skill: assessing and treating

Fitness: assessing and treating

Respiratory: assessing and treating

Pain: assessing and treating

\section{Prevention module}

Data collection

Global mapping tool

Prevention of $\mathrm{SCl}$ through prevention of road traffic crashes (RTCs)

Prevention of tetraplegia from diving into shallow water

$\mathrm{SCl}$ falls

\section{Occupational therapists' and assistive technologists' module}

Personal ADLs

Instrumental ADLs

Functional mobility

Hand function

Wheelchair mobility and seating

Home modifications

Abbreviations: $\mathrm{ADL}$, activities of daily living; $\mathrm{SCl}$, spinal cord injury. 

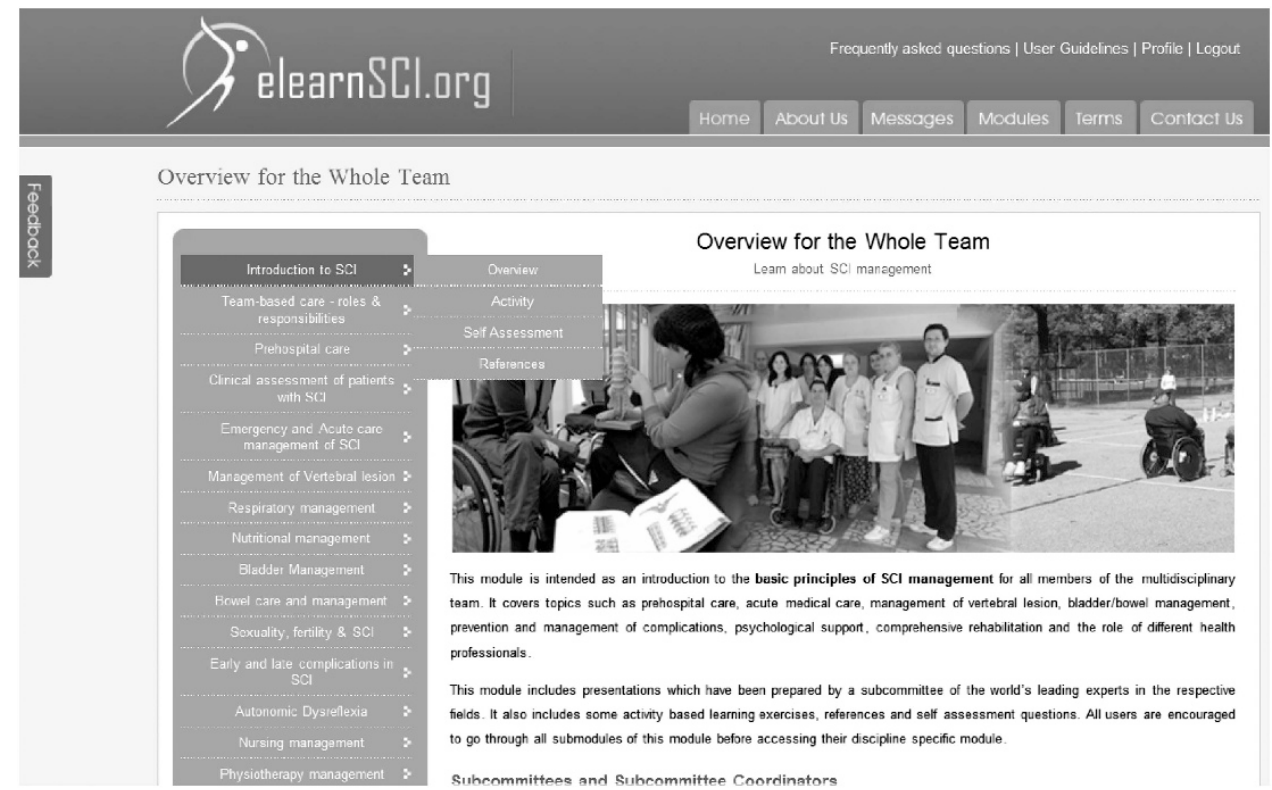

Figure 1 A screen shot from www.elearnSCl.org illustrating the splash page for the module titled: 'Overview for the Whole Team'. The side menu bar is for accessing the submodules. Each submodule comprises an overview, activity, self-assessment questions and references. A full color version of this figure is available at the Spinal Cord journal online.

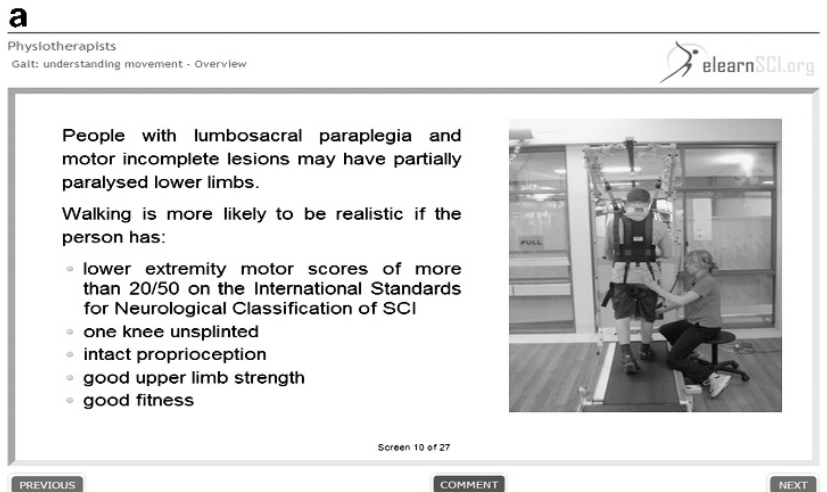

b

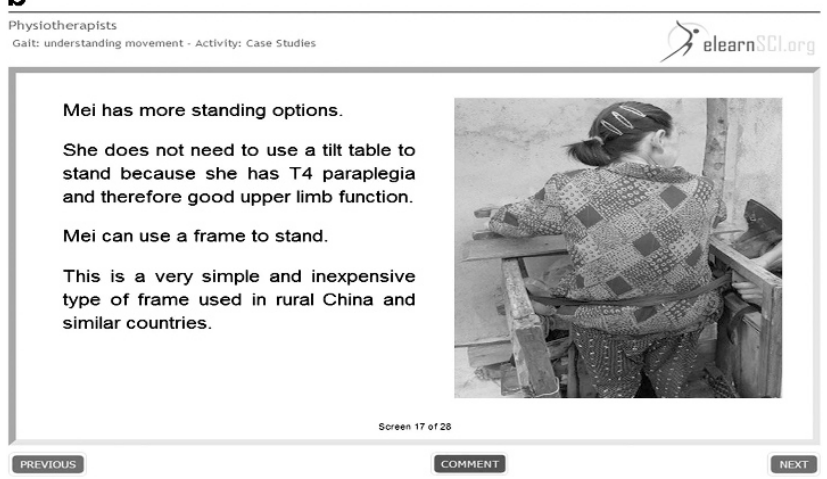

Figure 2 Two screen shots from www.elearnSCl.org illustrating the inclusion of both costly and inexpensive rehabilitation solutions. This approach was adopted to ensure the content of the website is applicable in high- and low-resource countries. A full color version of this figure is available at the Spinal Cord journal online.

leading experts from that particular field across the globe. In addition, the content is based on up-to-date SCI research and will be periodically revised as new evidence emerges.

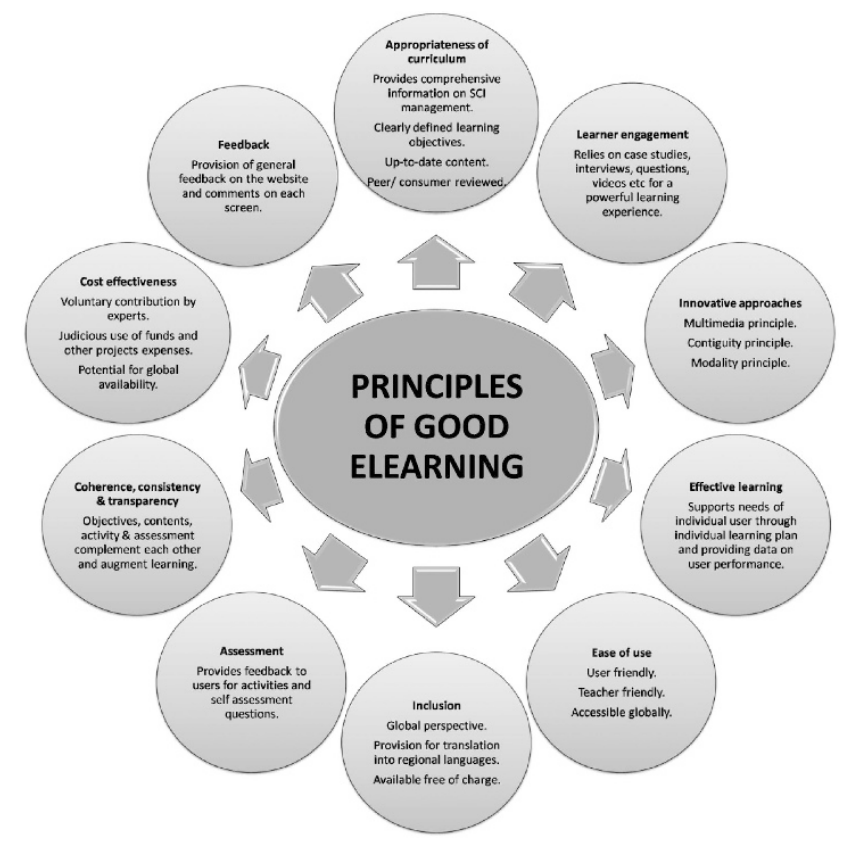

Figure 3 The 10 principles of effective learning which www.elearnSCl.org conforms to.

The first module titled 'Overview for the whole team' provides information essential for all members of the team. The disciplinespecific modules have the additional information that each discipline requires. This structure ensures that the content is directed at the appropriate level for each discipline.

The resource also has the potential to facilitate cross-training of professionals because everyone has access to all the discipline-specific modules in the resource. Cross-training is particularly important in low-resource countries, where limited number of professionals may be providing all types of multi-disciplinary care. 
a

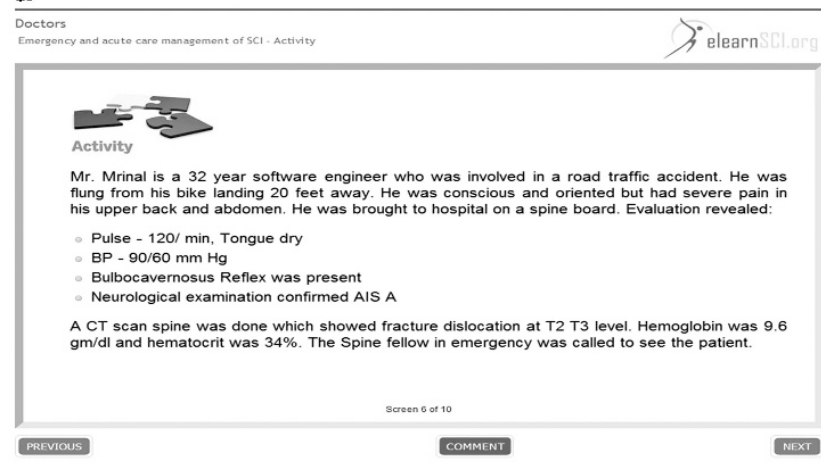

b

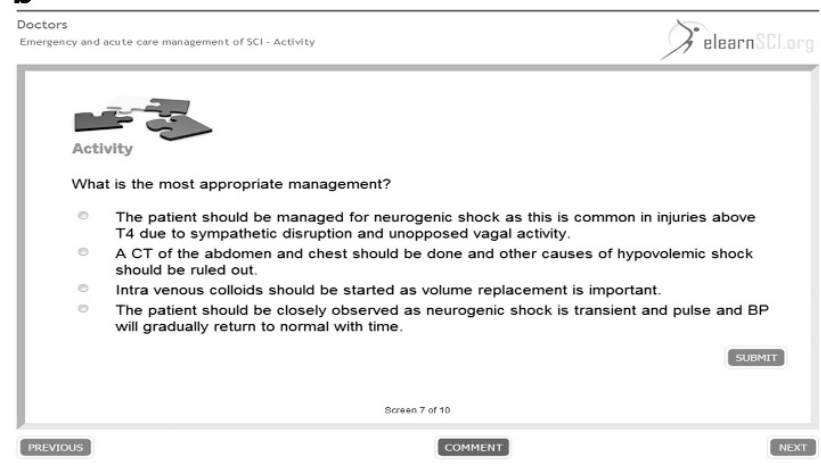

C

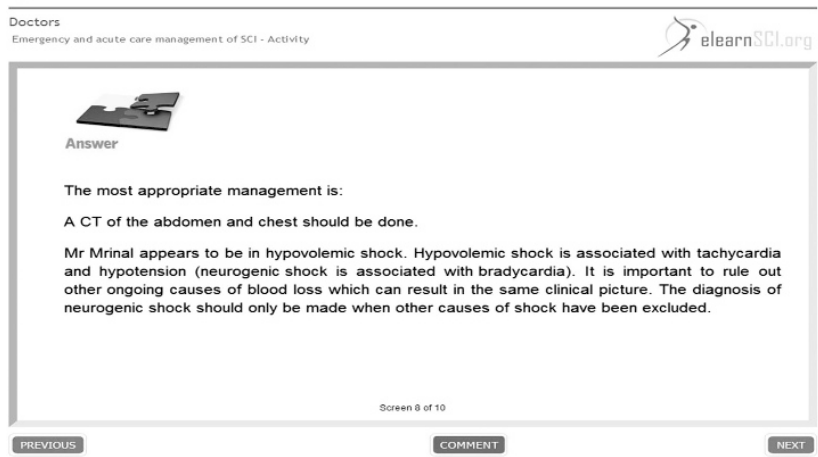

Figure 4 Three screen shots from www.elearnSCl.org illustrating the various types of interactive screens. These types of screens have been included to actively engage the learner. A full color version of this figure is available at the Spinal Cord journal online.

A workshop in New Delhi provided peer review and optimised the content of the educational modules. An evaluation is planned wherein the resource will be pilot tested with a sample of target users. Knowledge, skills and confidence will be assessed before and after reading the modules. The pre- and post-test measures will track the change in participants' understanding of the issues covered in the learning resource and enable an assessment of the potential impact of the learning content.

Learning objectives. The learning objectives for each submodule have been clearly defined using Blooms Taxonomy. ${ }^{12}$ Although they generally address the cognitive domain (that is, knowledge), some also address the affective (that is, emotion) and psychomotor (that is, skills) domains. The inclusion of all three types of objectives reflects a

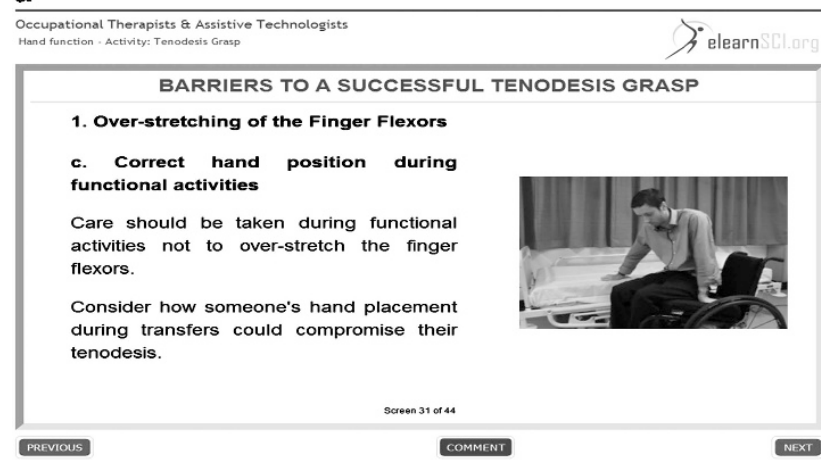

b

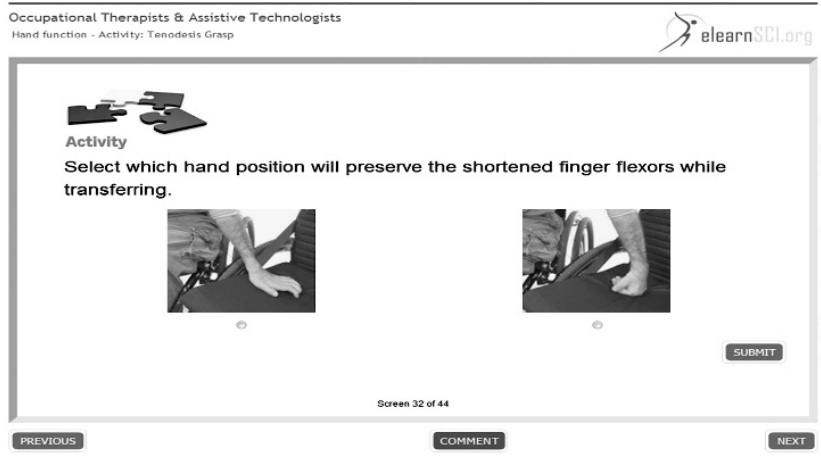

C

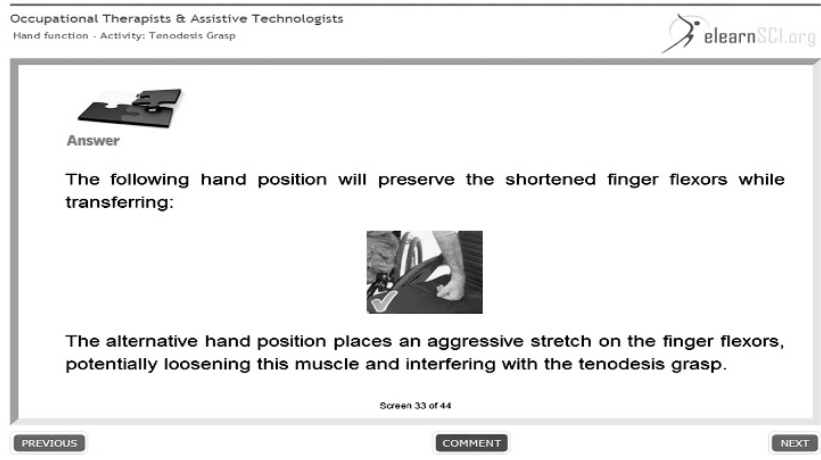

Figure 5 Three screen shots from www.elearnSCl.org illustrating use of innovative approaches (multimedia and contiguity principle) and learner engagement principles of e-learning. A full color version of this figure is available at the Spinal Cord journal online.

the underlying purpose of the learning experience, that is, to change/ improve knowledge, emotion and skills.

Peer/consumer reviewed. The appropriateness of the content has been reviewed by peers and consumers.

\section{Learner engagement}

Users are actively engaged in the learning process (Figure 4). ${ }^{3}$ They are not passive recipients of information. They learn by reviewing real case studies, listening to interviews from experts, answering questions and viewing photos, videos ${ }^{4}$ (Figure 5 ) and material from various SCI centres. It is these features that set this website apart from other sources of information and text books about SCI.

References and links detail the original source of the content. Direct pathways/links to other education resource material are also provided. 
Interactive screens are an integral part of the activities. These engage the learner by providing immediate feedback.

Users can view their assessment scores for completed submodules providing motivation to cover the submodules, which are still pending or retake the assessments to improve their scores. They can also interact or discuss progress with their supervisors, lecturers or mentors and can email their improved scores to them.

\section{Innovative approaches}

Different types of illustrations, including still graphics such as line drawings, charts and photographs are employed through the modules to enhance the user experience. ${ }^{3}$ Motion graphics such as video have been incorporated into the resource as well. Research has shown that adding graphics to words can improve learning. ${ }^{4,5}$ This is popularly known as the multimedia principle ${ }^{6}$ (Figure 5). Illustrations that are congruent with the instructional message have been used.

Learning occurs when new information is encoded into long-term memory. ${ }^{7}$ According to Dual Encoding theory, content communicated with text and graphics sends two codes - a verbal code and a visual code. Learning is increased by the two opportunities for encoding into long-term memory. ${ }^{7}$ In addition, the use of graphics and illustrations helps learners for whom English may not be their first language and reduces the need for detailed text.

Contiguity refers to the alignment of graphics and text on the screen. ${ }^{6}$ In accordance with the contiguity principle, text related to the graphics is placed close to each other on the screens in www.elearnSCI.org (Figure 5).

Research has also shown that explaining graphics with audio improves learning (Modality principle ${ }^{6}$ ). However, as learning is actually depressed when a graphic is explained by a combination of text and narration that reads the text, this combination has been avoided. ${ }^{6}$ There is an option of adding voice to some of the screens in the future. Whether or not this option is adopted will be determined by the outcome of research that has been planned to study the effect of voice overlay on learning.

\section{Effective learning}

Users have a wide variety of learning styles and needs. www.elearnSCI.org supports the needs of the individual. ${ }^{3}$ Learners can go through the resource at their own comfortable pace, thus enabling them to learn the content effectively. Further, the summary of the assessments in the profile helps them reflect on their performance and focus effectively on topics they have not mastered well. They can also ask for the help of their supervisors, lecturers or mentors on these topics.

\section{Ease of use}

User friendly. The resource is user friendly and easy to navigate. ${ }^{3,8}$ There is an option for users to access user guidelines or contact the administrator.

Teacher friendly. Even though it is an e-learning resource, teachers will find the content very useful for teaching purposes. In settings with few resources where students may not have easy internet access, teachers can use the resource for teaching in their classes.

Accessibility. The resource is accessible globally.

\section{Inclusion}

The international peer review process ensured that the information available is applicable globally irrespective of the cultural and socioeconomic background of the region (Figure 2). Further, users from all economic backgrounds can access the resource because it is available free of charge.

The resource will continue to evolve over the coming years and findings from a planned evaluation will help guide it. Like other e-learning tools, elearnSCI.org is a 'living', dynamic and evolving body of information that will be continually kept up-to-date and thus should stay on the cutting edge of SCI care today and in the future. There are plans to evaluate the content in a systematic manner on a regular basis (every 3 years) incorporating feedback, periodic evaluations, suggestions, new technologies and new standards of care as they evolve. The revisions would be proposed by the subcommittees as part of three yearly evaluation and would be reviewed by the editorial committee.

In addition, there are plans to translate the content into different regional languages. Translations into Spanish and French have already been proposed. ISCoS along with its regional affiliated societies would be involved in translation process following the principles outlined by Biering-Sorensen et al. ${ }^{13}$ This would ensure the availability of the resource to a gradually increasing proportion of non-English speaking health professionals. ISCoS further proposes to disseminate information about the resource in different parts of the world and especially in less resourced areas through its affiliated societies.

\section{Assessment}

Users can get feedback for their attempts at activities as well as self-assessment questions. ${ }^{3}$ On attempting activity-based learning exercises, immediate feedback is given indicating if the response is correct or incorrect. On submitting the answers for self-assessment questions, the assessment of performance is displayed on the screen. The assessment experience enhances learning. ${ }^{9}$ It may also motivate users to make an attempt to carefully go through the submodules, for which they have not scored well in the self assessment questions.

\section{Coherent, consistent and transparent}

Care has been taken to ensure coherence and consistency in the way the objectives, contents, activities and assessments complement each other and augment learning. ${ }^{3}$ For example, the overview and activities are consistent with the objectives, and the self-assessment assesses the extent to which the objectives are met for a particular user.

\section{Cost effectiveness}

Web-based learning is, generally, a cost-effective way of providing education, hence its growing popularity within universities and educational institutions. ${ }^{3,10,11}$ It is cost-effective because it minimises the need for costly face-to-face teaching and avoids the expense associated with bringing large numbers of learners together for formal classes.

There were two main costs associated with developing www.elearnSCI.org. These were the costs of developing the interface and the costs of bringing the experts together for editorial meetings. The costs associated with developing the interface were minimised by engaging an Indian-based IT company. The costs of developing the content were minimal because those responsible for this have donated their time and expertise. Recovery of the initial and ongoing expenses is not foreseen as the resource is available free of charge consistent with ISCoS' aim to ensure widespread information dissemination. A study on cost-effectiveness could be done subsequently (for example, at the first anniversary of the launch when the number of users over the year would be known) but it is difficult to imagine a more cost-effective means of providing a learning resource with the similar potential for global availability. 


\section{Feedback}

Users have the ability to provide general feedback. ${ }^{3}$ In addition, at the bottom of each screen there is the opportunity to provide specific feedback on that particular screen.

\section{LIMITATIONS OF THE RESOURCE}

Though elearnSCI.org is a valuable tool for information dissemination, like other e-learning resources, it cannot replace the traditional learning methods. An over-emphasis on e-learning without incorporating adequate 'hands-on' learning can compromise the understanding of the basics of management.

\section{SUMMARY}

Despite advances, SCI management still remains one of the most complex challenges facing healthcare professionals. Moreover, there is a lack of professional development opportunities for health professionals involved in the management SCI and limited access to up-todate SCI training and learning materials/resources. In order to bridge this gap, ISCoS took the initiative to develop www.elearnSCI.org, a web-based educational resource that addresses the educational needs of all disciplines involved in the management of SCI. It is relevant to students as well as new and experienced SCI practitioners. ${ }^{14}$

The resource comprises seven modules, each consisting of various submodules. Each submodule covers a specific topic and includes a presentation, activity-based learning activities, references and selfassessment questions.

Experts of ISCoS and affiliated societies were involved in the compilation of the resource through subcommittees and review through Education, Scientific and Editorial Committees. On the basis of up-to-date SCI research, the educational resource is applicable globally, has a consumer input and is available free of charge. The resource has been developed taking into consideration the principles of effective e-learning.

\section{DATA ARCHIVING}

There were no data to deposit.

\section{CONFLICT OF INTEREST}

The authors declare no conflict of interest.

\section{ACKNOWLEDGEMENTS}

We acknowledge the contribution of all the experts who have contributed voluntarily for the development of www.elearnSCI.org. We are grateful to the collaborating partners of ISCoS for their whole hearted support. A special thanks to the whole ISCoS family-the Executive for their guidance and support, the Education Committee for conceiving the project and overseeing it, the Scientific Committee for their input for the whole project, the General Body for supporting the whole project and the www.elearnSCI.org Editorial Committee for putting in endless hours both in person at Delhi and via e-mail communications. We also acknowledge the contribution of Grapes software for their substantial efforts to develop the web platform and upload the educational resource, and Resonance for developing the www.elearnSCI.org audio-visual. We specially acknowledge the Indian Spinal Injuries Centre Editorial Committee and core team (Dr Kalidutta Das, Dr Ankur Nanda, Dr Gururaj Sangondimath, Dr Bibhudendu Mohapatra, Dr Vikas Tandon, Dr Nishit Patel, Dr ML Bansal, Dr Darshan Gautam, Dr Ameer Theruvath, Dr Rajat Mahajan, Dr Vijayanth, Dr Rahul Kaul, Dr Pallav Bhatia, Dr Ajay Sharma, Ms Rajesh Sharawat, Ms Shashi Rautela, Ms Neema Bisht and Ms Amita Kashyap) for their enormous contribution. The principal funding organisation for www.elearnsci.org was Access to Health Care, without whose support the project would not have been possible. Funding was also received from New South Wales Lifetime Care and Support Scheme, The Australian and New Zealand Spinal Cord Society, Trust Access Healthcare, Royal North Shore Hospital and The Prince of Wales Hospital.

1 Consortium for Spinal Cord Medicine. Early acute management in adults with spina cord injury: a clinical practice guideline for health-care professionals. J Spinal Cord Med 2008; 31: 403-479.

2 Bloemen-Vrencken JHA, de Witte LP, Post MWM. Follow-up care for persons with spinal cord injury living in the community: a systematic review of interventions and their evaluation. Spinal Cord 2005: 43. 462-475.

3 Anderson J, McCormick R. Ten Pedagogic Principles of E-learning, Observatory for New Technologies and Education. http://www.icwe.net/oeb special/OEB Newsportal/wpcontent/uploads/2011/09/10-Principles-for-Successful-E-learning.pdf.

4 Romanov K, Nevgi A. Do medical students watch video clips in eLearning and do these facilitate learning? Med Teach 2007; 29: 484-488.

5 Choules AP. The use of elearning in medical education: a review of the current situation. Postgrad Med J 2007; 83: 12-16.

6 Clark R 2002, Six principles of effective e-Learning: What works and why The e-Learning Developer's Journal 1 -10. http://www.learningsolutionsmag.com/articles/ 384/. (Accessed Nov 10 2012).

7 Mayer RE. Memory and Information Process. In: Reynolds WM and Miller GJ (eds) Handbook of Psychology, Educational Psychology. John Wiley \& Sons Inc: New Jersey, pp 51, 2003.

8 Levesque DR, Kelly G. Meeting the challenge of continuing education with eLearning. Radiol Manage 2002; 24: 40-43.

9 Docherty C, Hoy D, Topp H, Trinder K. Using Elearning techniques to support problem based learning within a clinical simulation laboratory. Stud Health Technol Inform 2004; 107: 865-868.

10 Mazzoleni MC, Maugeri C, Rognoni C, Cantoni A, Imbriani M. Is it worth investing in online continuous education for healthcare staff? Stud Health Technol Inform 2012; 180: 939-943

11 Mazzoleni MC, Rognoni C, Pagani M, Imbriani M. Online education in a large scale rehabilitation institution. Stud Health Technol Inform 2012; 174: 67-71.

12 Bloom BS, Engelhart MD, Furst EJ, Hill WH, Krathwohl DR. Taxonomy of educational objectives: the classification of educational goals; Handbook ILongmans, Green: Cognitive Domain New York, 1956.

13 Biering-Sørensen F, Alexander MS, Burns S, Charlifue S, DeVivo M, Dietz V et al. Executive committee for the international $\mathrm{SCl}$ standards and data sets. recommendations for translation and reliability testing of international spinal cord injury data sets. Spinal Cord 2011; 49: 357-360.

14 Docherty C, Hoy D, Topp H, Trinder K. eLearning techniques supporting problem based learning in clinical simulation. Int J Med Inform 2005; 74: 527-533. 